UDC 691-492; 691.223; 691.213.2

Author: DANILOV Victor Evgenyevich, Postgraduate student, Northern (Arctic) Federal University named after M.V. Lomonosov, Institute of Construction and Architecture, Department of Composite Materials and Engineering Ecology; Northern Dvina Emb. 17, Arkhangelsk, Russia, 163002;

v.danilov@narfu.ru;

Author: AYZENSTADT Arcady Mikhailovich, Doctor of Chemistry, Professor, Honored Worker of Higher Education of the Russian Federation, Head of Composite Materials and Engineering Ecology Department, Northern (Arctic) Federal University named after M.V. Lomonosov, Institute of Construction and Architecture, Department of Composite Materials and Engineering Ecology; Northern Dvina Emb. 17, Arkhangelsk, Russia, 163002; a.isenshtadt@narfu.ru

\title{
COMPREHENSIVE APPROACH TO THE ASSESSMENT OF NANOSIZED FRACTIONS OF POLYDISPERSE SYSTEMS OF CRUSHED ROCKS
}

\section{Extended Abstract:}

The results of size determination for mechanically dispersed rock (polymineral sand, basalt) based on methods of dynamic light scattering, gas (nitrogen) sorption and electron microscopy were comparatively analyzed. The experimental samples are obtained by mechanical dispersion of raw materials on the planetary and colloidal grinding mills. There is a high correlation in the obtained experimental results. Method of dynamic light scattering makes it possible to analyze dimensional characteristics of polydispersed systems with high amount of nano- and submicron particles with sufficient sedimentation stability in the dispersion medium. Characteristics of particles size calculated by the specific surface area of the studied systems' consider the content of the micro-size fraction. The effective diameter of the particles was proposed as the characteristics of their morphological structure. The calculation of the effective diameter is based on the particle mass.

Key words: rocks, polymineral sand, basalt, mechanical dispersing, dynamic light scattering, gas sorption, electron microscopy, particle size, specific surface area, effective diameter. 


\section{MACHINE-READABLE INFORMATION ON CC-LICENSES (HTML-CODE) IN METADATA OF THE PAPER}

$<$ a rel="license" href="http://creativecommons.org/licenses /by/4.0/" $><$ img alt="Creative Commons License" style="borderwidth:0" src="https://i.creativecommons.org/l/by/4.0/88x31.png" $/></ \mathrm{a}><$ br $/><$ span xmlns:dct="http://purl.org/dc/ terms/" href="http://purl.org/dc/dcmitype/Text" property="dct:title" rel="dct:type" $>$ Comprehensive approach to the assessment of nanosized fractions of polydisperse systems of crushed rocks. </span $>$ by $<$ a xmlns:cc="http://creativecommons. $\mathrm{org} / \mathrm{ns} \# "$ href="Nanotehnologii v stroitel'stve $=$ Nanotechnologies in Construction. 2016, Vol. 8, no. 3, pp. 97-110. DOI: dx.doi.org/10.15828/2075-8545-2016-8-3-97-110. " property="cc:attributionName" rel="cc:attributionURL" $>$ Danilov V.E., Ayzenstadt A.M. $</ \mathrm{a}>$ is licensed under a $<$ a rel="license" href="http://creativecommons.org/licenses/by $/ 4.0 / ">$ Creative Commons Attribution 4.0 International License $</ \mathrm{a}>.<\mathrm{br} />$ Based on a work at $<$ a xmlns:dct="http://purl.org/dc/terms $/ "$ href=" http://nanobuild.ru/en_EN/nanobuild-3-2016/" rel="dct:source" $>$ http://nanobuild.ru/en_EN/nanobuild-3-2016/</ $\mathrm{a}>$. $<$ br $/>$ Permissions beyond the scope of this license may be available at $<$ a xmlns:cc="http://creativecommons.org $/ \mathrm{ns} \# "$ href="v.danilov@narfu.ru"rel="cc:morePermissions">v.danilov@narfu.ru</a $>$.

\section{References:}

1. Tretyakov Yu.D., Goodilin E.A. Osnovnye napravlenija fundamental'nyh i orientirovannyh fundamental'nyh issledovanij v oblasti nanomaterialov [Major directions of basic and dedicated basic research in the area of nanomaterials]. Al'ternativnaja jenergetika i jekologija [Alternative energy and ecology]. 2009. № 6. pp. 39-67. (In Russian).

2. Lesovik V.S., Strokova $V . V$. O razvitii nauchnogo napravlenija «Nanosistemy v stroitel'nom materialovedenii» [On the development of a scientific direction «Nanosystems in building materials»]. Stroitel’nye Materialy [Construction Materials]. 2006. № 9. Application Nauka № 8, pp. 18-20. (In Russian).

3. Korolev E.V. Nanotehnologija v stroitel'nom materialovedenii. Analiz sostojanija i dostizhenij. Puti razvitija [Nanotechnology in material science. Analysis of achievements and current state]. Stroitel'nye Materialy [Construction Materials]. 2014. № 11. pp. 47-50.

4. Karpov A.I. Development of nanotechnologies in construction - a task which is of great importance for scientists and engineers. Nanotechnologies in Construction: A Scientific Internet-Journal, Moscow, CNT «NanoStroitelstvo». 2013, Vol. 5, no. 2, pp. 43-54. Available at: http://www.nanobuild.ru/magazine/nb/Nanobuild_2_2013.pdf (Accessed 01.02.2016). (In Russian).

5. Lesovik V.S., Frolova M.A., Ayzenshtadt A.M. Poverhnostnaja aktivnost' gornyh porod [Surface Activity of Rocks]. Stroitel’nye Materialy [Construction Materials]. 2013. № 11. pp. 71-74.

6. Veshniakova L.A., Ayzenstadt A.M., Frolova M.A. Otsenka poverhnostnoj aktivnosti vysokodispersnogo syr'ja dlja kompozicionnyh stroitel'nyh materialov [An evaluation of the surface activity of high-disperse raw materials for composite building materials]. Fizika i himija obrabotki materialov [Physics and chemistry of materials treatment]. 2015. № 2 . pp. 68-72.

7. Artamonova O.V., Sergutkina O.R., Korotkikh D.N., Chernishov E.M. Sol-gel synthesis of $\mathrm{SiO}_{2}$ nanosized particles for cement stone structure modifying. Nanotechnologies in Construction: A Scientific Internet-Journal, Moscow, CNT «NanoStroitelstvo». 2010, Vol. 2, no. 1, pp. 9-17. Available at: http://www.nanobuild.ru/magazine/nb/Nanobuild_1_2010.pdf (Accessed 01.02.2016). (In Russian). 
8. Smirnov V.A., Korolev E.V., Albakasov A.I. Size effects and topological characteristics of nanomodified composites. Nanotechnologies in Construction: A Scientific InternetJournal, Moscow, CNT «NanoStroitelstvo». 2011, Vol. 3, no. 4, pp. 17-27. Available at: http://www.nanobuild.ru/magazine/nb/Nanobuild_4_2011.pdf (Accessed 01.02.2016). (In Russian).

9. Frolova M.A.,Tutygin A.S., Ayzenstadt A.M. Application of the thermodynamic approach to the assessment of the surface energy state of the disperse materials. Nanotechnologies in Construction: A Scientific Internet-Journal, Moscow, CNT «NanoStroitelstvo». 2011, Vol. 3, no. 6, pp. 13-25. Available at: http://www.nanobuild.ru/magazine/nb/Nanobuild_6_2011.pdf (Accessed 01.02.2016). (In Russian).

10. Abramovskaya I.R., Ayzenstadt A.M., Frolova M.A. et al. The energy of highly dispersed rock composites. Nanotechnologies in Construction: A Scientific Internet-Journal, Moscow, CNT «NanoStroitelstvo». 2013, Vol. 5, no. 3, pp. 28-37. Available at: http://www. nanobuild.ru/ magazine/nb/Nanobuild_3_2013.pdf (Accessed 01.02.2016). (In Russian).

11. Veshnyakova A.L., Ayzenshtadt A.M. Optimizacija granulometricheskogo sostava smesej dlja poluchenija melkozernistyh betonov [Optimization of Granulometric Composition of Mixes for Fine Concretes]. Promyshlennoe i grazhdanskoe stroitel'stvo [Industrial and Civil Engineering]. 2012. № 10. pp. 19-22. (In Russian).

12. Levin A.V. Basic principles of particle size analysis. GC «Energolab». Available at: http:// www.beton-center.ru/files/66/ (Accessed 01.02.2016). (In Russian).

13. Summ B.D., Ivanova N.I. Kolloidno-himicheskie aspekty nanohimii - ot Faradeja do Prigozhina [Colloid-chemical aspects of nanochemistry - From Faraday to Prigogine]. Vestnik Moskovskogo Universiteta. Chemistry. 2001; 42(5): pp. 300-305. (In Russian).

14. Gregg S., Sing K. Adsorption, Surface Area and Porosity. Trans. from English, $2^{\text {nd }}$ Edition. Moscow, Mir.1984. 306 p.

15. Almjasheva O.V., Fedorov B.A., Smirnov A.V., Gusarov V.V. Razmer, morfologija i struktura chastic nanoporoshka dioksida cirkonija, poluchennogo $v$ gidrotermal'nyh uslovijah [Size, morphology and structure of the particles of zirconia nanopowder obtained under hydrothermal conditions]. Nanosistemy: fizika, himija, matematika [Nanosystems: Physics, Chemistry, Mathematics]. 2010. Vol. 1. no. 1. pp. 26-36. (In Russian).

Dear Colleagues!

THE REFERENCE TO THIS PAPER HAS THE FOLLOWING CITATION FORMAT:

Danilov V.E., Ayzenstadt A.M. Comprehensive approach to the assessment of nanosized fractions of polydisperse systems of crushed rocks. Nanotehnologii v stroitel'stve $=$ Nanotechnologies in Construction. 2016, Vol. 8, no. 3, pp. 97-110. DOI: dx.doi.org/10.15828/2075-8545-2016-8-3-97-110. (In Russian). 
УДК 691-492; 691.223; 691.213.2

Автор: ДАНИЛОВ Виктор Евгеньевич, аспирант кафедры композиционных материалов и строительной экологии, ФГАОУ ВО «Северный (Арктический) федеральный университет имени М.В. Ломоносова», Институт строительства и архитектуры; наб. Северной Двины, 17, Архангельск, Россия, 163002; v.danilov@narfu.ru;

Автор: АЙЗЕНШТАДТ Аркадий Михайлович, профессор, д.х.н., заслуженный работник высшей школы РФ, заведующий кафедрой композиционных материалов и строительной экологии, ФГАОУ ВО «Северный (Арктический) федеральный университет имени М.В. Ломоносова», Институт строительства и архитектуры; наб. Северной Двины, 17, Архангельск, Россия, 163002; a.isenshtadt@narfu.ru

\section{КОМПЛЕКСНЫЙ ПОДХОД К ОЦЕНКЕ НАНОРАЗМЕРНЫХ ФРАКЦИЙ ПОЛИДИСПЕРСНЫХ СИСТЕМ ИЗМЕЛЬЧЕННЫХ ГОРНЫХ ПОРОД}

АННОТАЦИЯ К СТАТЬЕ (АВТОРСКОЕ РЕЗЮМЕ, РЕФЕРАТ):

Проведен сравнительный анализ результатов определения размеров механически диспергированных горных пород (полиминеральный песок, базальт), выполненных методами: динамического рассеяния света, сорбции газа (азота) и электронной микроскопии. Опытные пробы получены механическим диспергированием сырьевых материалов на планетарной и коллоидной мельницах. Полученные экспериментальные результаты показали высокую сходимость. Метод динамического рассеяния света позволяет проводить анализ размерных характеристик полидисперсных систем с высоким содержанием нано- и микроразмерных частиц, обладающих достаточной седиментационной устойчивостью в используемой дисперсионной среде. Размерные характеристики частиц, рассчитанные по величине удельной поверхности анализируемых систем, учитывают содержание микроразмерной фракции. Для характеристики морфологии частиц предложено использовать величину их эффективного диаметра, расчет которого осуществляется с учетом массы частицы.

Ключевые слова: горные породы, полиминеральный песок, базальт, механическое диспергирование, динамическое светорассеяние, сорбция газа, электронная микроскопия, размер частиц, удельная поверхность, эффективный диаметр. 
МАшИНОЧИТАЕМАЯ ИНФОРМАЦИЯ О СС-ЛИЦЕНЗИИ В МЕТАДАННЫХ СТАТЬИ (НTML-КОД):

$<$ a rel="license" href="http://creativecommons.org/licenses/by/4.0/"><img alt="Лицензия Creative Commons" style="border-width:0" src="https://i.creativecommons.org/l/by/4.0/88x31.png" / $></ \mathrm{a}><$ br $/>$ Произведение "<span xmlns:dct="http://purl.org/dc/terms/" href="http://purl.org/dc/dcmitype/Text" property="dct:title" rel="dct:type"> Комплексный подход к оценке наноразмерных фракций полидисперсных систем измельченных горных пород </span>》 созданное автором по имени < $<$ xmlns:cc="http://creativecommons.org/ns\#" href="Нанотехнологии в строительстве. - 2016. - Том 8, № 3. - C. 97-110. - DOI: dx.doi.org/10.15828/2075-8545-2016-8-3-97-110." property="cc:attributionName" rel="cc:attributionURL"> Данилов В.Е., Айзенштадт А.M. $<$ /а $>$, публикуется на условиях $<$ a rel="license" href="http://creativecommons.org/licenses/by/4.0/">лицензии Creative Commons «Attribution» ( ААтрибуция») 4.0 Всемирная $</ \mathrm{a}>$. $<\mathrm{br} />$ Основано на произведении с $<$ a xmlns:dct="http://purl.org/dc/terms/" href="http:// nanobuild.ru/ru_RU/nanobuild-3-2016/" rel="det:source">http://nanobuild.ru/ru_RU/nanobuild-3-2016/</a $>$. $<$ br $/>$ Pa3решения, выходящие за рамки данной лицензии, могут быть доступны на странице <a xmlns:cc="http://creativecommons. org/ns\#" href="v.danilov@narfu.ru" rel="cc:morePermissions">v.danilov@narfu.ru $</ \mathrm{a}>$.

начительный интерес к исследованию наносистем на основе горных пород различного генезиса, отличающихся химическим и минералогическим составом, строением и морфологией поверхности, вызван необычными физико-химическими, механическими, теплофизическими и другими свойствами композитов, полученных с использованием этих образований. Данный факт открывает широкие перспективы их практического применения [1, 2]. В настоящее время создаются технологии производства наноматериалов и их применения, основанные на использовании нанодисперсного сырья и наносистем различного состава и строения, однако спектр подобных технологий в строительной индустрии пока не велик $[3,4]$. Области практического применения нанодисперсного вещества, полученного при обработке горных пород, только формируются $[5,6]$. Это связано в числе прочих причин и с тем, что получение достоверных данных по размерному распределению частиц, их морфологии, с учетом полидисперсности всей системы (с существенной долей вещества наноразмерного уровня) представляет значительную проблему. Можно подчеркнуть, что создание технологий производства материалов на основе нанопорошков невозможно без достоверных сведений об их размерных и структурных характеристиках.

Анализ размерных, морфологических и структурных характеристик наночастиц различной природы свидетельствует, что они в значительной степени зависят от метода и условий их получения [7-11]. Следует также отметить, что, как справедливо указывают авторы [8], высокая стоимость большинства наномодифицирующих добавок является основным фактором, который делает необходимыми предвари-

http://nanobuild.ru 
тельные исследования моделей возможных наносистем. В этом плане вопросы с оценкой агрегативной устойчивости частиц этих систем приобретают первостепенное значение. Кроме того, авторы [8] предлагают в качестве критерия агрегативной устойчивости использовать энергию теплового движения частиц, отнесенную к поверхности структурной единицы $\left(\sigma_{m}\right)$ :

$$
\sigma_{m}=\gamma \frac{k T}{d^{2}}
$$

где $\gamma \sim 10$ (безразмерный коэффициент), $k$ - постоянная Больцмана $\left(1,38.10^{-23}\right.$ Дж/К), T - температура в $\kappa, d$ - размер структурной единицы. При этом, если $\sigma_{m}>0,01$ Дж/ $\mu^{2}$, система является агрегативно устойчивой.

Использование выражения (1) предопределяет работы, связанные с определением размерных характеристик частиц.

Полидисперсность и разнородность формы частиц, являющиеся следствием механического диспергирования полиминеральных горных пород, делают процесс анализа размеров частиц комплексным вопросом. В этом плане необходимо решать следующую задачу: как выразить одним числовым значением размер частицы, которая имеет несколько величин, характеризующих ее размер. Автор [12] предлагает для этой цели использовать теорию эквивалентной сферы, которая всегда дает одну размерную характеристику - диаметр эквивалентной сферы $\left(d_{\text {экв }}\right)$, рассчитываемый по массе образца. Таким образом можно получить одно универсальное число для диаметра сферы, которая имеет такую же массу, как масса объекта (частицы). Если исходить из того, что средняя степень дисперсности $\left(D_{c p}\right)$ системы (величина, обратно пропорциональная среднему радиусу частиц) равна отношению площади поверхности частицы к ее объему [13], то с учетом значений истинной плотности высокодисперсной системы $(\rho)$ и ее удельной поверхности $\left(S_{y \partial}\right)$ формулу для расчета диаметра эквивалентной сферы можно получить в следующем виде:

$$
d_{э к в}=\frac{2}{\rho S_{y d}} .
$$

Определение размеров, морфологии наночастиц осуществляют такими методами как, например, электронная микроскопия. Вместе с тем, полезными могут быть и методы, базирующиеся на оптических 
свойствах частиц и интегральных характеристиках дисперсных систем. Это методы, основанные на анализе динамического светорассеяния [11], или метод определения удельной площади поверхности порошков, в частности, из анализа процессов сорбции газов [14, 15]. Данные методы имеют как определенные преимущества, так и ограничения. Так, для определения распределения вещества нанодисперсного уровня по размерам в настоящее время широкое распространение получил метод, основанный на измерении динамического светорассеяния. Этим методом можно определить размерные характеристики частиц порошка с достаточно широким распределением по размерам. В тех случаях, когда известны морфологические характеристики наночастиц, а нанопорошок имеет не высокое значение полидисперсности, распределение частиц по размерам может быть определено по данным о его удельной поверхности.

Однако, для достоверной оценки размера нанодисперсного вещества в объеме полидисперсной системы, необходимо использовать комплекс взаимодополняющих методов. Это, как минимум, динамическое рассеяние света и удельная поверхность. В данной работе с использованием подобного комплексного подхода анализируется размерная характеристика механически диспергированных горных пород различного генезиса.

В качестве объектов исследования были выбраны: речной полиминеральный песок (породообразующие минералы: кварц, кальцит, полевые шпаты, гипс, слюда) крупностью зерен от 1,6 до 1,8 мм, предварительно отмытый от глинистых включений, и базальтовая крошка, отобранная с месторождения базальта горы Мяндухи в Плесецком районе Архангельской области. Образцы высушивали и доводили до постоянной массы при температуре $105^{\circ} \mathrm{C}$.

Для базальта среднюю плотность определяли методом взвешивания в воде парафинированных образцов. Для песка истинную плотность определяли пикнометрическим методом.

Размер частиц диспергированного вещества определяли на анализаторе размера субмикронных частиц и -потенциала Delsa Nano Series Zeta Potential and Submicron Particle Size Analyzers (DelsaNano) методом измерения динамического светорассеяния. Удельная площадь поверхности анализируемых высокодисперсных проб рассчитывалась по теории БЭТ на основании измерений сорбции азота на установке Autosorb- 
iQ-MP. Для сравнительного анализа размерных характеристик образцов в высокодисперсном состоянии были получены фотографии методом растровой электронной микроскопии (РЭМ) на электронном микроскопе Zeiss SIGMA VP (электронная микроскопия проводилась в ЦКП САФУ «Арктика»).

Процесс диспергирования проводили на планетарной шаровой Retsch PM100 и коллоидной IKA magic LAB мельницах. Для получения высокодисперсных образцов песка помол осуществлялся в две стадии с последовательным использованием шаровой и коллоидной мельниц. Образец высокодисперсного базальта был получен только на шаровой мельнице. Для каждого из исследуемых образцов подбирали оптимальный режим диспергирования, позволяющий получить минимальный размер частиц и хорошую воспроизводимость результатов. Требуемая степень дисперсности песка достигалась при сухом диспергировании на планетарной шаровой мельнице. Продолжительность помола составила 120 мин, скорость вращения ротора 420 об/мин (использовались 20 карбидвольфрамовых размольных тел). Последующее дробление водной суспензии песчаного образца производилось на коллоидной мельнице, продолжительность помола 30 мин, скорость вращения - 16000 об/мин. Средний размер частиц составил 97,8 нм (92\% ) (см. табл.).

Базальт, являясь весьма твердой и абразивной породой, имеет ограничение измельчения на коллоидной мельнице. Поэтому требуемая степень дисперсности достигалась на планетарной шаровой мельнице при мокром диспергировании продолжительностью 120 мин., скорости вращения - 420 об/мин ( 25 размольных тел). Средний размер частиц составил 94,9 нм $(89 \%)$ (см. табл.).

таблица

Фракционный состав исследованных образцов

\begin{tabular}{|c|c|c|c|c|c|c|c|}
\hline \multicolumn{7}{|c|}{ Размер по фракциям, нм/содержание, \% } & $\begin{array}{c}\text { Средний } \\
\text { размер, } \\
\text { нм }\end{array}$ \\
\hline № 1 & № 2 & № 3 & № 4 & № 5 & № 6 & № 7 & \multicolumn{7}{|c|}{ Песок } \\
\hline \multicolumn{7}{|c|}{ Базальт } \\
\hline $81,1 / 25$ & $88,7 / 20$ & $97,1 / 16$ & $106,2 / 12$ & $116,2 / 9$ & $127,1 / 6$ & $139,0 / 4$ & 97,8 \\
\hline \multicolumn{7}{|c|}{} \\
\hline $77,0 / 17$ & $83,7 / 17$ & $90,9 / 16$ & $98,9 / 14$ & $107,5 / 11$ & $116,8 / 8$ & $127,0 / 6$ & 94,9 \\
\hline
\end{tabular}


Сравнение протоколов определения фракционного состава (рис. 1, 2), полученных на анализаторе DelsaNano, показало, что базальт обладает более высокой размолоспособностью, чем песок.

Результаты измерения удельной поверхности $\left(S_{y \partial}\right)$ высокодисперсных систем песка и базальта позволили получить следующие значения данного параметра (соответственно): $8580 \mathrm{~m}^{2} /$ кг и $6450 \mathrm{~m}^{2} /$ кг. Разница в величинах удельной поверхности анализируемых образцов песка и базальта при практически равных значениях дисперсности, на наш взгляд, объясняется отличием плотностей материалов и, как следствие, разным

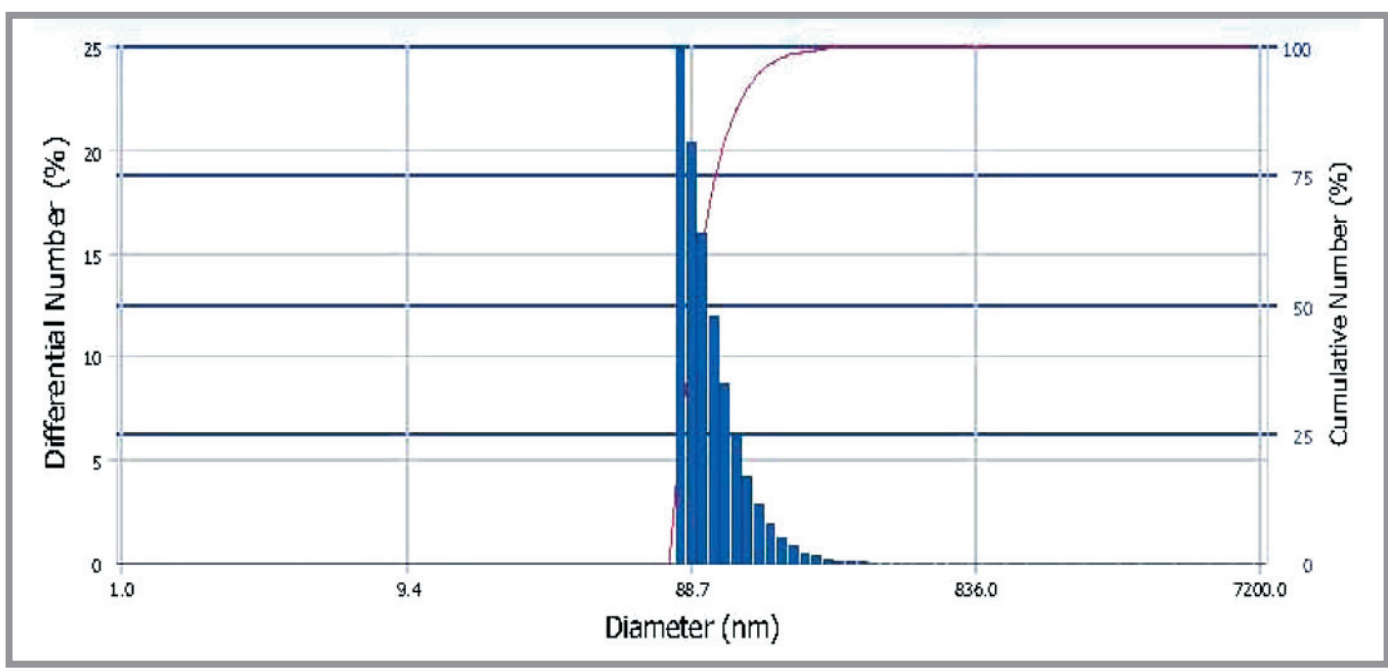

Рис. 1. Фракционное распределение частиц диспергированного песка

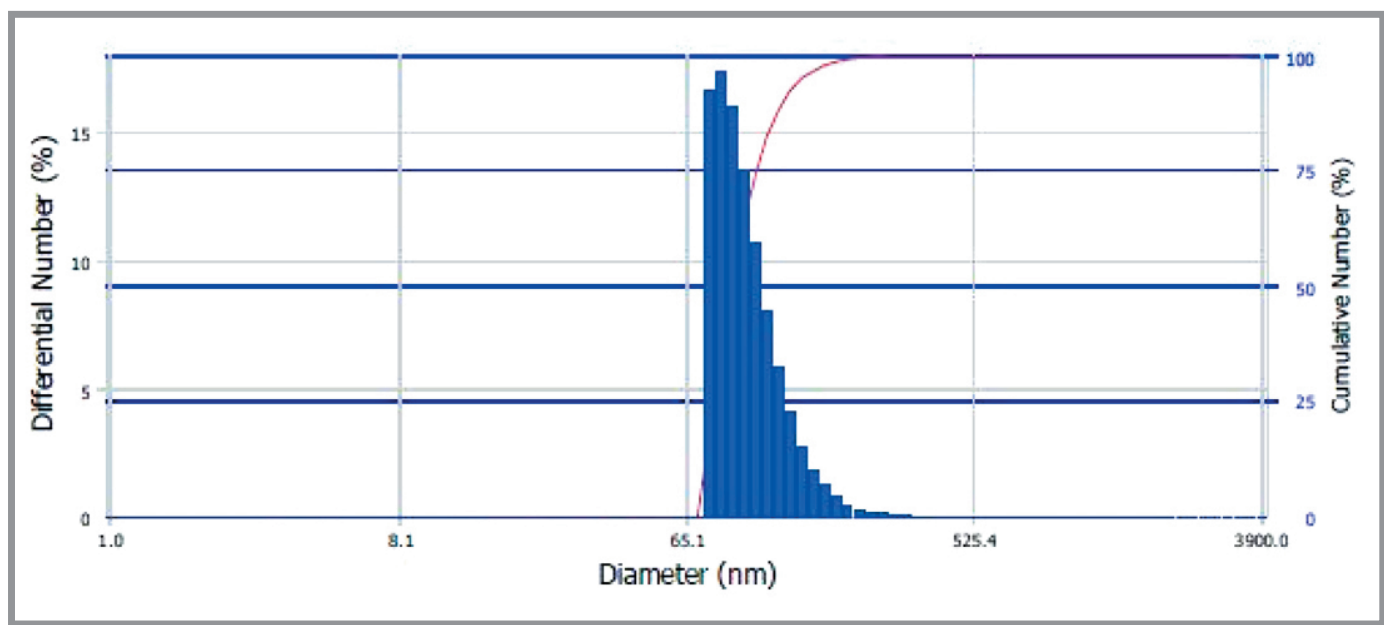

Рис. 2. Фракционное распределение частиц диспергированного базальта 
количеством частиц в исследуемых навесках. Кроме того, эта разница может быть связана с шероховатостью поверхности частиц песка.

Плотность исходных образцов исследуемых горных пород состави-

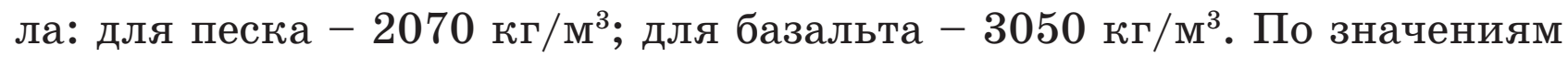
удельной поверхности и плотности опытных образцов были рассчитаны величины среднего размера частиц $\left(d_{c p}\right)$ анализируемых высокодисперсных систем горных пород по известному выражению (исходя из предположения о том, что частицы имеют сферическую форму):

$$
d_{c p}=\frac{6}{\rho S_{y \partial}} .
$$

Результаты расчета дали следующие размерные характеристики исследуемых систем: средний размер частиц песка составил 338 нм, базальта - 305 нм.

Анализ формы и морфологии частиц высокодисперсных проб, выполненный по микрофотоснимкам (рис. 3), показал, что для всех проб наряду с наноразмерными частицами отмечается наличие их агломератов, а также зерен микронного диапазона, что всегда характерно для диспергированных систем, применяемых для производства строительных материалов. Эти крупные частицы не могут быть определены методом фотонно-корреляционной спектроскопии, т.к. они не обладают седиментационной устойчивостью и в процессе измерения не находятся во взвешенном состоянии.
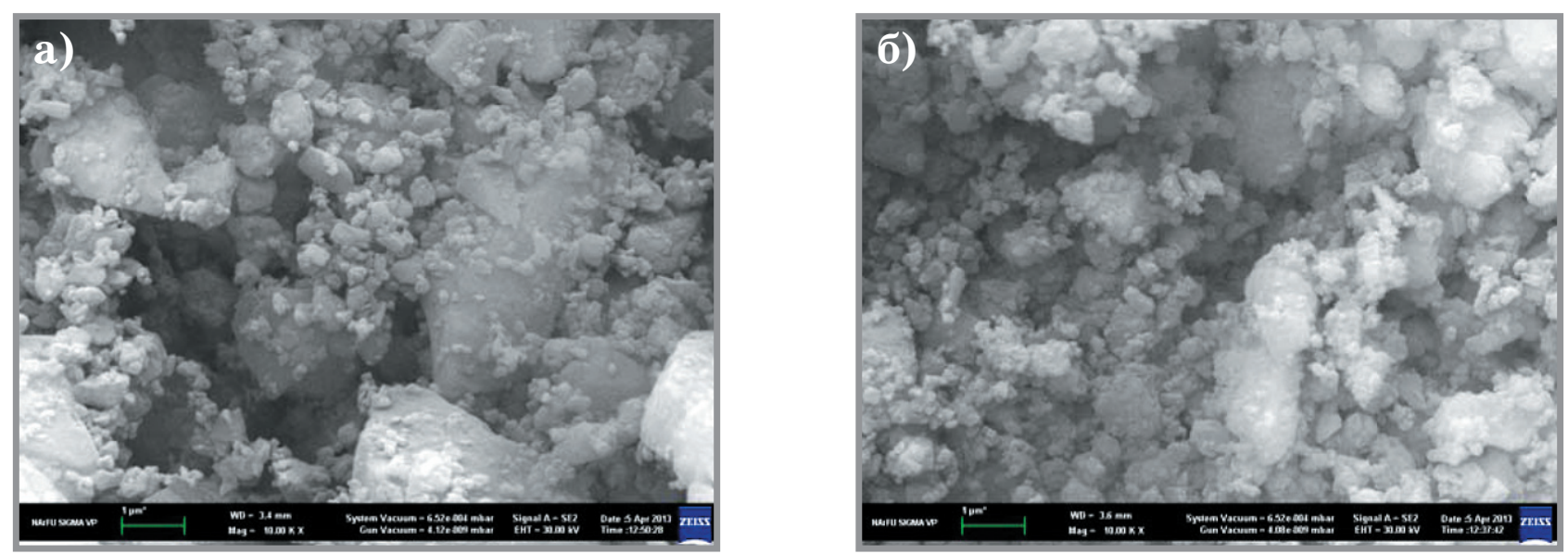

Рис. 3. Микроструктура диспергированных образцов:

а - песка; б - базальта

http://nanobuild.ru 
Вычисленные по уравнению (2) значения эффективных диаметров частиц песка и базальта позволили получить следующие величины: 112 нм и 102 нм, что хорошо согласуется с данными метода динамического светорассеяния.

Расчет критерия $\sigma_{m}$ по выражению (1) показал, что в зависимости от размерных характеристик данная величина изменяется на порядок от $10^{-5}$ (для 100 нм диапазона) до $10^{-6}$ (для 300 нм диапазона) Дж/ $\mathrm{m}^{2}$, что характерно для кинетически слабо устойчивых систем. Следовательно, при определении размерных характеристик высокодисперсных образцов горных пород необходимо учитывать временной фактор, связанный с седиментационными свойствами анализируемых объектов.

Сопоставляя результаты исследований, полученные методами динамического светорассеяния, сорбции газов и электронной микроскопии, можно выделить следующие положения:

1. Экспериментальная реализация метода динамического рассеяния света позволяет проводить анализ размерных характеристик высокодисперсных систем, обладающих достаточной седиментационной устойчивостью в используемой дисперсионной среде. Результаты измерений в нашем случае характеризуют состав наноразмерной фракции системы, для которой средний размер частиц песка и базальта составил 97,8 и 94,9 нм, а количественное содержание данных фракций - 92\% и $89 \%$ соответственно.

2. Рассчитанный эффективный диаметр частиц проанализированных проб по величинам плотности горных пород и удельной поверхности хорошо согласуется с результатами, полученными методом динамического рассеяния света. Данный факт может свидетельствовать о том, что частицы исследуемых горных пород по морфологическим признакам близки к сферической форме.

3. Расчет размерных характеристик частиц исследуемых систем, проведенный по полученным экспериментальным данным определения удельной поверхности этих систем, дополняет результаты метода динамического светорассеяния. Так, средний размер частиц для высокодисперсного порошка песка по данным его удельной поверхности, равный 338 нм, характеризует диапазон фракций, включая микро-, субмикро- и нанофракции. Для системы из высокодисперсного порошка базальта аналогичная усредненная размерная характеристика равна 305 нм. 
4. Электронная микроскопия исследуемых высокодисперсных систем, на наш взгляд, подтверждает вышеприведенные положения.

5. Оценка агрегативной устойчивости данных систем показала, что величина критерия $\sigma_{m}$ изменяется в пределах от $10^{-5}$ до $10^{-6}$ Дж/ $^{2}$. Следовательно, измерение методом динамического рассеяния света размеров частиц суспензии возможно настолько долго, насколько они могут находиться в суспензии и не седиментировать.

Резюмируя полученные результаты, следует отметить, что только комплексный подход к определению размеров частиц в полидисперсных системах с высоким содержанием ультрадисперсного вещества, базирующийся на использовании методов динамического светорассеяния, сорбции газов и сравнительном анализе полученных этими методами результатов, может дать надежную информацию о размерных характеристиках и фракционном распределении.

Работа выполнена при поддержке Министерства образования и науки РФ в рамках базовой части государственного задания 2016-2017 г2. (проект № 3636 ).

\section{УВАЖАЕМЫЕ КОЛЛЕГИ!}

ПРИ ИСПОЛЬЗОВАНИИ МАТЕРИАЛА ДАННОЙ СТАТЬИ

ПРОСИМ ДЕЛАТЬ БИБЛИОГРАФИЧЕСКУЮ ССЫЛКУ НА НЕЁ:

Данилов B.E., Айзенштадт A.M. Комплексный подход к оценке наноразмерных фракций полидисперсных систем измельченных горных пород // Нанотехнологии в строительстве. - 2016. - Том 8, № 3. - C. 97-110. - DOI: dx.doi. org $/ 10.15828 / 2075-8545-2016-8-3-97-110$.

\section{Dear Colleagues!}

THE REFERENCE TO THIS PAPER HAS THE FOLLOWING CITATION FORMAT:

Danilov V.E., Ayzenstadt A.M. Comprehensive approach to the assessment of nanosized fractions of polydisperse systems of crushed rocks. Nanotehnologii v stroitel'stve $=$ Nanotechnologies in Construction. 2016, Vol. 8, no. 3, pp. 97-110. DOI: dx.doi.org/10.15828/2075-8545-2016-8-3-97-110. (In Russian). 


\section{Библиографический список:}

1. Третьяков Ю.Д., Гудилин Е.А. Основные направления фундаментальных и ориентированных фундаментальных исследований в области наноматериалов // Альтернативная энергетика и экология. - 2009. - №6. - С. 39-67.

2. Лесовик B.C., Строкова В.В. О развитии научного направления «Наносистемы в строительном материаловедении» // Строительные материалы. - 2006. № 9. / Наука № 8. - С. 18-20.

3. Королев E.B. Нанотехнология в строительном материаловедении. Анализ состояния и достижений. Пути развития // Строительные материалы. - 2014. №11. - С. 47-50.

4. Карпов А.И. Развитие нанотехнологий в строительстве - актуальнейшая задача ученых и инженеров // Нанотехнологии в строительстве. - 2013. - Том 5, № 2. - C. 43-54. - URL: http://nanobuild.ru/ magazine/nb/Nanobuild_2_2013. pdf (дата обращения: 01.02.2016).

5. Лесовик B.С., Фролова М.А., Айзенштадт А.М. Поверхностная активность горных пород // Строительные материалы. - 2013. - № 11. - С. 71-74.

6. Вешнякова Л.А., Айзенштадт А.М., Фролова М.А. Оценка поверхностной активности высокодисперсного сырья для композиционных строительных материалов // Физика и химия обработки материалов. - 2015. - № 2. - С. 68-72.

7. Арталонова О.В., Сергуткина О.Р., Коротких Д.Н., Чернышов Е.М. Зольгель синтез наноразмерных частиц $\mathrm{SiO} 2$ для модифицирования структуры цементного камня // Нанотехнологии в строительстве. - 2010. - Том 2, № 1. C. 9-17. - URL: http://nanobuild.ru/magazine/nb/Nanobuild_1_2010.pdf (дата обращения: 01.02.2016).

8. Слирнов B.A., Королев E.В., Альбакасов А.И. Размерные эффекты и топологические особенности наномодифицированных композитов // Нанотехнологии в строительстве. - 2011. - Toм 3, № 4. - C. 17-27. - URL: http://nanobuild.ru/ magazine/nb/Nanobuild_4_2011.pdf (дата обращения: 01.02.2016).

9. Фролова М.A., Тутыгин А.С., Айзенштадт А.M. Применение термодинамического подхода к оценке энергетического состояния поверхности дисперсных материалов // Нанотехнологии в строительстве. - 2011. - Том 3, № 6. - С. 1325. - URL: http://nanobuild.ru/magazine/nb/ Nanobuild_6_2011.pdf (дата обращения: 01.02.2016).

10. Абраловская И.Р., Айзенштадт А.М., Фролова М.А. и др. Энергетика высокодисперсных композитов горных пород // Нанотехнологии в строительстве. 2013. - Tом 5, № 3. - C. 28-37. - URL: http://nanobuild.ru/magazine/nb/ Nanobuild_3_2013.pdf (дата обращения: 01.02.2016).

11. Вешнякова Л.А., Айзенштадт A.M. Оптимизация гранулометрического состава смесей для получения мелкозернистых бетонов // Промышленное и гражданское строительство. - 2012. - № 10. - С. 19-22. 
12. Левин А.В. Основные принципы анализа размера частиц. ГК «Энерголаб». URL: http://www.beton-center.ru/files/66/ (дата обращения 01.02.2016).

13. Сулл Б.Д., Иванова Н.И. Коллоидно-химические аспекты нанохимии - от Фарадея до Пригожина // Вестн. Моск. ун-та. Серия 2. Химия. - 2001. - Т. 2, № 5. - C. 300-305.

14. Грег С., Синг К. Адсорбция, удельная поверхность, пористость / Пер. с англ., 2-е издание - М.: Мир, 1984. - 306 с.

15. Альляиева О.В., Федоров Б.А., Слирнов А.В., Гусаров В.В. Размер, морфология и структура частиц нанопорошка диоксида циркония, полученного в гидротермальных условиях // Наносистемы: физика, химия, математика. - 2010. T. 1, № 1. - C. 26-36. 